\title{
Endorhizal Fungi in Ranunculus from Western and Arctic Canada: Predominance of Fine Endophytes at High Latitudes
}

\author{
X.J. Walker ${ }^{1,3}$, J.F. Basinger ${ }^{2}$ and S.G.W. Kaminskyj ${ }^{*}, 1$ \\ ${ }^{I}$ Department of Biology, University of Saskatchewan, 112 Science Place, Saskatoon SK S7N 5E2, Canada \\ ${ }^{2}$ Department of Geological Sciences, University of Saskatchewan, 114 Science Place, Saskatoon SK S7N 5E2, Canada \\ ${ }^{3}$ Current address: Department of Botany, University of British Columbia, Vancouver BC V6T 1Z4, Canada
}

\begin{abstract}
Ranunculus roots were sampled across a latitudinal transect encompassing $52{ }^{\circ} \mathrm{N}$ and $82{ }^{\circ} \mathrm{N}$, for years spanning 1963-2007. Samples from 2004 and later were preserved in formalin; earlier samples were taken from herbarium accessions. Roots were examined for colonization by arbuscular mycorrhizae, fine endophyte, and septate endophyte fungi using lactofuchsin-stained material imaged with epifluorescence microscopy. Endorhizal quantitation was assessed for each endorhizal morphotype. Roots from High Arctic $\left(79^{\circ} \mathrm{N}-82^{\circ} \mathrm{N}\right)$ and mid-latitude $\left(52^{\circ} \mathrm{N}-54^{\circ} \mathrm{N}\right)$ sites both contained all three endorhizal morphotypes; however, overall fungal colonization was almost three-fold higher in midlatitude samples. Most Ranunculus root colonization (29\% of the root length) in High Arctic samples was from fine endophyte fungi, whereas fine endophyte colonization was $~ 20 \%$ of root length in mid-latitude roots. In contrast, arbuscular mycorrhizal colonization was $2 \%$ of root length in High Arctic samples and $57 \%$ in mid-latitude samples. Septate endophyte colonization was $11 \%$ and $36 \%$ of root length for High Arctic and mid-latitude samples, respectively. These values are consistent with our previous results for other taxa, and suggest that fine endophytes are important contributors to soil microbial diversity as related to plant survival and competitiveness in the high latitudes.
\end{abstract}

Keywords: Arctic tundra, epifluorescence microscopy, fine endophyte fungi, lactofuchsin staining, multiple quantitation microintersect method, mycorrhiza, septate endophyte fungi.

\section{INTRODUCTION}

Ranunculus includes annual or perennial, aquatic or terrestrial herbs found worldwide with exception of lowland tropical regions. It is frequently found in moist to marshy locations [1]. This project is part of a larger research effort to understand the role of endorhizal fungi in plants growing in tundra of the Canadian High Arctic. Mycorrhizal symbioses had been thought to be rare for plants growing in arctic and alpine sites [2-4]. More recently, arbuscular mycorrhizal (AM) symbioses were found associated with plants from some High Arctic sites [5,6], and Allen et al. [7] showed that some High Arctic Asteraceae had similar types and abundances of AM as congeneric plants from mid-latitudes. Ormsby et al. [8] showed that herbarium specimens provided similar qualitative and quantitative results to formalin fixed samples [7], opening the possibility for studies ranging over time and space, without the logistical difficulties inherent in research in remote areas.

Allen et al. [7] found that Ranunculus roots from Axel Heiberg Island contained fine endophyte (FE) fungi, which are likely to be related to AM (reviewed in [9]). FE fungi are somewhat enigmatic due to visualization challenges that result from their very small size and because propagules are difficult to isolate for experimental studies [9]. FEs stain

*Address correspondence to this author at the Department of Biology, University of Saskatchewan, 112 Science Place, Saskatoon SK S7N 5E2, Canada; Tel: 306-966-4422; E-mail: susan.kaminskyj@usask.ca with trypan blue $[6,9,10]$ but their hyphal networks are much better contrasted by lactofuchsin staining and fluorescence microscopy [7]. Unlike AM and ectomycorrhizal fungi $[11,12]$, FE distribution and abundance have seldom been documented in a non-experimental setting $[6,10]$. FE arbuscules have been suggested to have nutrient-transfer capabilities [13], making them likely to be functionally comparable to AM fungi. If $\mathrm{FE}$ fungi were abundant in particular environments, they could contribute substantially to plant survival and competitiveness, regardless of the presence of AM fungi.

In this study, we used high-sensitivity confocal epifluorescence microscopy visualization as first presented in Allen et al. [7] and the multiple quantitation microintersect (MQM) method first described in Ormsby et al. [8] to characterize endorhizal fungal colonization of Ranunculus plants collected across a latitudinal transect that spanned northern Ellesmere Island to southern Saskatchewan. Most intriguingly, we found that FE fungi were predominant in plants collected from high-latitude sites, suggesting an underappreciated contributor to tundra ecosystem stability and sustainability.

\section{MATERIAL AND METHODS}

\section{Specimens}

A total of 9 species of the genus Ranunculus were assessed (Ranunculus cymbalaria Pursh; Ranunculus hyper- 
Table 1. Collection Sites ${ }^{\text {a }}$ for this Study

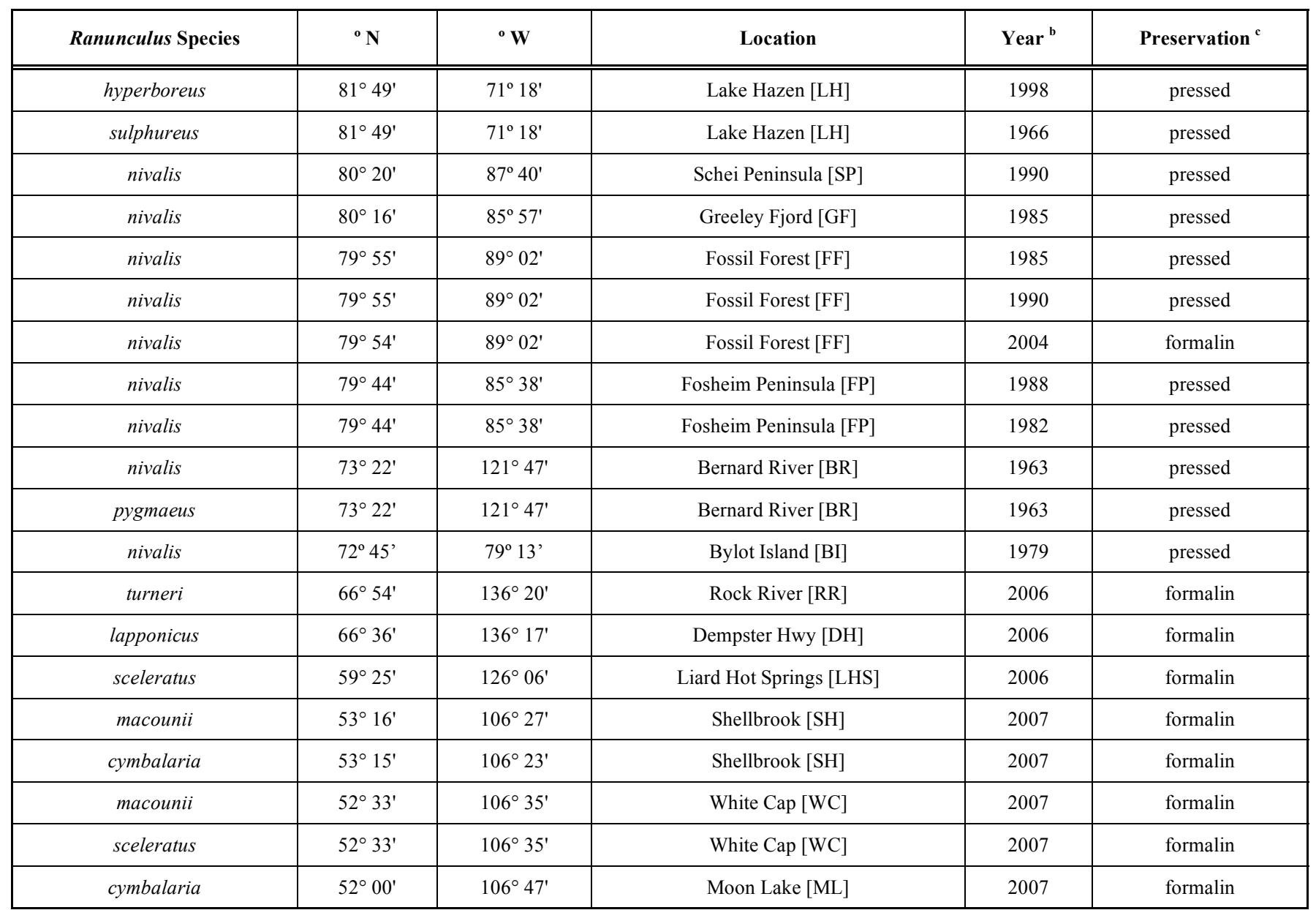

a Also see Fig. (1).

b Samples collected prior to 2004 were curated as pressed specimens in the W.P. Fraser Herbarium, University of Saskatchewan; sampled with permission.

c See Materials and Methods.

boreus Rottbøll; Ranunculus lapponicus L.; Ranunculus macounii Britton; Ranunculus nivalis L.; Ranunculus pygmaeus Wahlenberg; Ranunculus sceleratus L.; Ranunculus sulphureus Solander, Ranunculus turneri Greene). Details of plant collection sites are summarized in Table $\mathbf{1}$ and Fig. (1). Plants collected in 2004, 2006, and 2007 were preserved in buffered $3.7 \%$ formalin as described in Allen et al. [7] and stored at $4{ }^{\circ} \mathrm{C}$. Voucher specimens for these plants were also preserved as herbarium sheets. Root samples from specimens collected between 1963 and 1990 were from the W. P. Fraser Herbarium (University of Saskatchewan) with permission. For roots sampled from herbarium specimens, typically at least $10 \mathrm{~cm}$ was used, but no more than $10 \%$ of the available material. Specimens were identified using [1, 14-16], and were verified at the W. P. Fraser Herbarium.

\section{Preparation}

Formalin-fixed root systems were cut into $1-2 \mathrm{~cm} \mathrm{seg-}$ ments, suspended in a large volume of water, and randomly sub-sampled as described in [7]. Samples were prepared for imaging as described in $[8,17]$ by staining cleared roots with lactofuchsin then mounting in polyvinyl alcohol - glycerol medium. Dried root specimens were prepared as described in [8].

\section{Imaging}

Stained roots were imaged using widefield epifluorescence microscopy and confocal epifluorescence microscopy as described in $[7,8,18]$.

\section{Quantification}

Endorhizal fungal abundance was scored using a multiple quantitative microintersect (MQM) method described previously [8, 17-19] and which was modified after [20]. Briefly, this method examines regularly spaced sites at $200 \mathrm{X}$ total magnification, or higher, and assesses each intersect for multiple fungal colonization morphotypes, which are recorded separately. Root systems were examined at a minimum of 50 regularly spaced intersects (typically 100300 , depending on the length of root available). For herbarium specimens, all of the root material that had been sampled was stained and examined. Each plant was considered as a separate experimental unit. Root intersects that lacked fungal colonization were used to determine total 


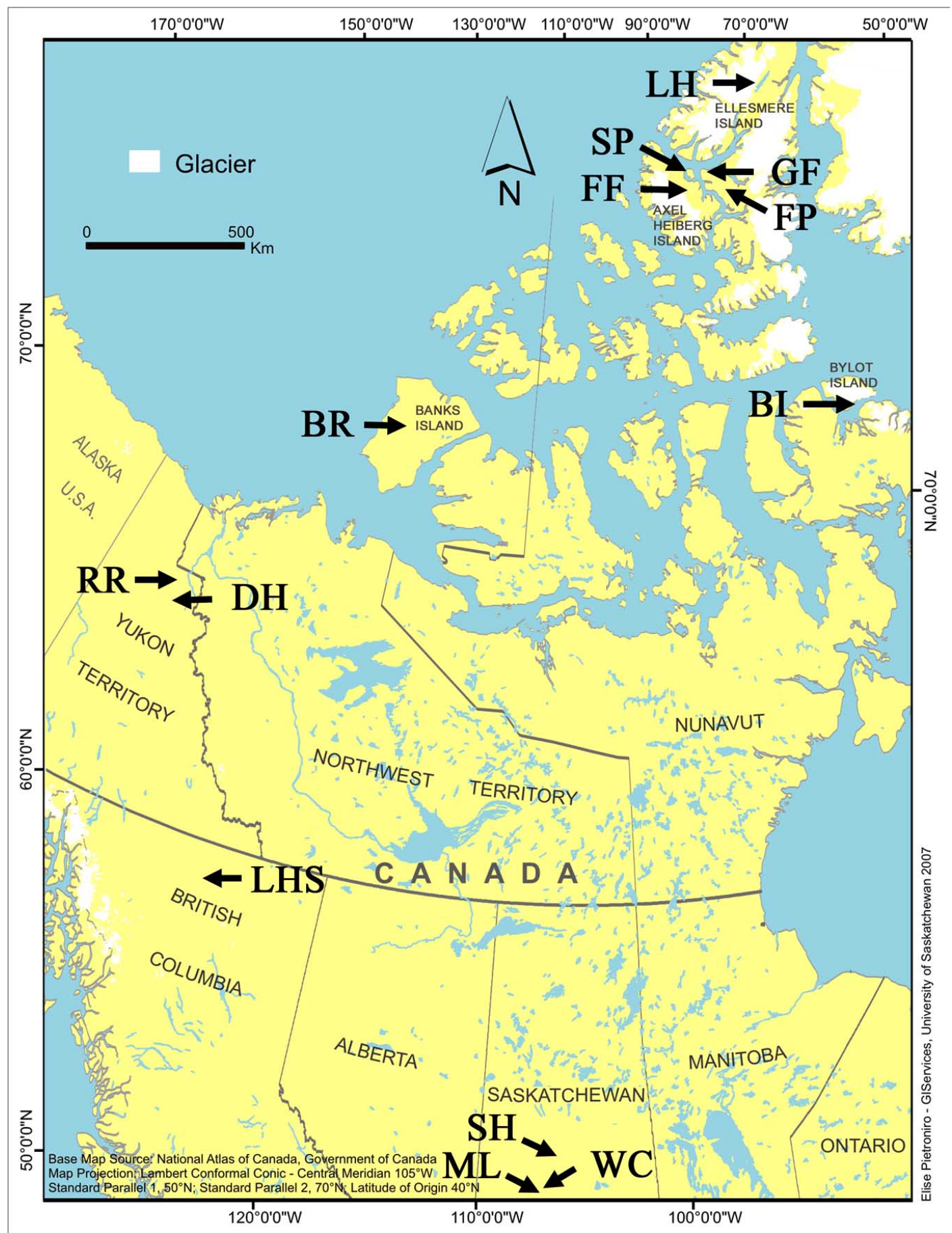

Fig. (1). Collection sites for this study. See also Table 1. National, provincial, territorial and island names are written on the map. Abbreviations for collection sites: BI, Bylot Island; BR, Bernard River; DH, Dempster Highway; FF, Fossil Forest; FP, Fosheim Peninsula; GF, Greeley Fjord; LH, Lake Hazen; LHS, Liard Hot Springs; ML, Moon Lake; RR, Rock River; SH, Shellbrook; SP, Schei Peninsula; WC, White Cap.

fungal colonization. Colonization is expressed as mean $\% \pm$ standard error.

\section{RESULTS}

This study included nine Ranunculus species from collection sites spanning $52^{\circ} \mathrm{N}-82^{\circ} \mathrm{N}$, and collection years spanning 1963 to 2007 . Roots of Ranunculus species con- tained a diversity of endorhizal fungi, mostly in three fungal morphotypes described in detail below: arbuscular mycorrhizae (AM); fine endophytes (FE); and septate endophytes (SE). On average, endorhizal fungi colonized 48 $\pm 6 \%$ of the root length, ranging from $0-100 \%$ for individual plants. Of the Ranunculus samples in Table 2, about one quarter had less than $20 \%$ colonization and one quarter had more than $80 \%$ colonization. Overall, endorhizal 
Table 2. Endorhizal Fungal Morphotypes ${ }^{\text {a }}$ and Abundance ${ }^{\text {b }}$ for Total Ranunculus Species

\begin{tabular}{|c|c|c|c|c|c|c|}
\hline${ }^{\circ} \mathbf{N}$ & Location $^{c}$ & Number of Plants & AMH & FEH & SEH & Total Colonization \\
\hline $81^{\circ} 54^{\prime}$ & Lake Hazen & 2 & $5.9 \pm 0.5$ & $0 \pm 0$ & $2.9 \pm 2.1$ & 9 \\
\hline $81^{\circ} 49^{\prime}$ & Lake Hazen & 2 & $5 \pm 0.5$ & $13.7 \pm 1.5$ & $13.7 \pm 9.5$ & 16 \\
\hline $81^{\circ} 49^{\prime}$ & Lake Hazen & 2 & $0.9 \pm 0.9$ & $15.3 \pm 3.4$ & $5.4 \pm 5.4$ & 22 \\
\hline $80^{\circ} 20^{\prime}$ & Schei Peninsula & 3 & $0 \pm 0$ & $31.9 \pm 4.6$ & $18.1 \pm 1.9$ & 49 \\
\hline $80^{\circ} 16^{\prime}$ & Greeley Fjord & 5 & $0 \pm 0$ & $7.9 \pm 2.6$ & $5.3 \pm 1.2$ & 13 \\
\hline $79^{\circ} 55^{\prime}$ & Fossil Forest & 2 & $0 \pm 0$ & $15.0 \pm 15.0$ & $8.5 \pm 8.5$ & 24 \\
\hline $79^{\circ} 54^{\prime}$ & Fossil Forest & 18 & $1.6 \pm 0.6$ & $49.5 \pm 7.2$ & $9.5 \pm 1.9$ & 56 \\
\hline $79^{\circ} 44^{\prime}$ & Fosheim Peninsula & 3 & $2.8 \pm 0.3$ & $57.7 \pm 5.6$ & $24.6 \pm 8.3$ & 68 \\
\hline $79^{\circ} 44^{\prime}$ & Fosheim Peninsula & 3 & $0 \pm 0$ & $26.7 \pm 6.0$ & $6.2 \pm 3.7$ & 33 \\
\hline $73^{\circ} 22^{\prime}$ & Bernard River & 5 & $2.6 \pm 0.9$ & $23.5 \pm 5.0$ & $1.3 \pm 0.5$ & 25 \\
\hline $66^{\circ} 36^{\prime}$ & Dempster Hwy & 2 & $77.4 \pm 2.5$ & $3.5 \pm 1.0$ & $0.9 \pm 0.5$ & 78 \\
\hline $59^{\circ} 25^{\prime}$ & Liard Hot Springs & 3 & $0 \pm 0$ & $0 \pm 0$ & $5.3 \pm 5.3$ & 5 \\
\hline $53^{\circ} 16^{\prime}$ & Shellbrook & 4 & $53.9 \pm 10.5$ & $17.4 \pm 5.4$ & $73 \pm 3.7$ & 92 \\
\hline $53^{\circ} 15^{\prime}$ & Shellbrook & 4 & $57.6 \pm 8.3$ & $6.6 \pm 1.9$ & $21.4 \pm 3.9$ & 69 \\
\hline $52^{\circ} 33^{\prime}$ & White Cap & 21 & $62.9 \pm 10.8$ & $27.2 \pm 4.4$ & $15.9 \pm 2.9$ & 81 \\
\hline $52^{\circ} 33^{\prime}$ & White Cap & 16 & $36.8 \pm 5.1$ & $23 \pm 3.2$ & $44.1 \pm 3.9$ & 81 \\
\hline $52^{\circ} 00^{\prime}$ & Moon Lake & 3 & $75.5 \pm 13.5$ & $23.4 \pm 9.1$ & $27.8 \pm 7.2$ & 92 \\
\hline $79^{\circ} \mathrm{N}-82^{\circ} \mathrm{N}$ & High Arctic & 42 & $2.0 \pm 0.7$ & $28.9 \pm 6.3$ & $11.4 \pm 2.2$ & 38 \\
\hline $52^{\circ} \mathrm{N}-54^{\circ} \mathrm{N}$ & Mid-latitude & 48 & $57.3 \pm 6.3$ & $19.5 \pm 3.6$ & $36.4 \pm 10.3$ & 83 \\
\hline
\end{tabular}

${ }^{a} \mathrm{AMH}$, arbuscular mycorrhizal hyphae; FEH, fine endophyte hyphae; SEH, septate endophyte hyphae

${ }^{\text {b }}$ Morphotypes were determined using lactofuchsin-stained roots examined with wide-field epifluorescence. Abundance was quantified for each plant using the multiple quantitative microintersect method, and expressed as mean percent abundance \pm standard error of the mean. Total abundance was determined by including the number of intersects that lacked fungal colonization. See Materials and Methods.

${ }^{\mathbf{c}}$ See Table 1 and Fig. (1).

Table 3. Comparison of Percent Endorhizal Colonization for Plants Studied from High-Latitude and Mid-Lati-tude Sites ${ }^{\text {a }}$

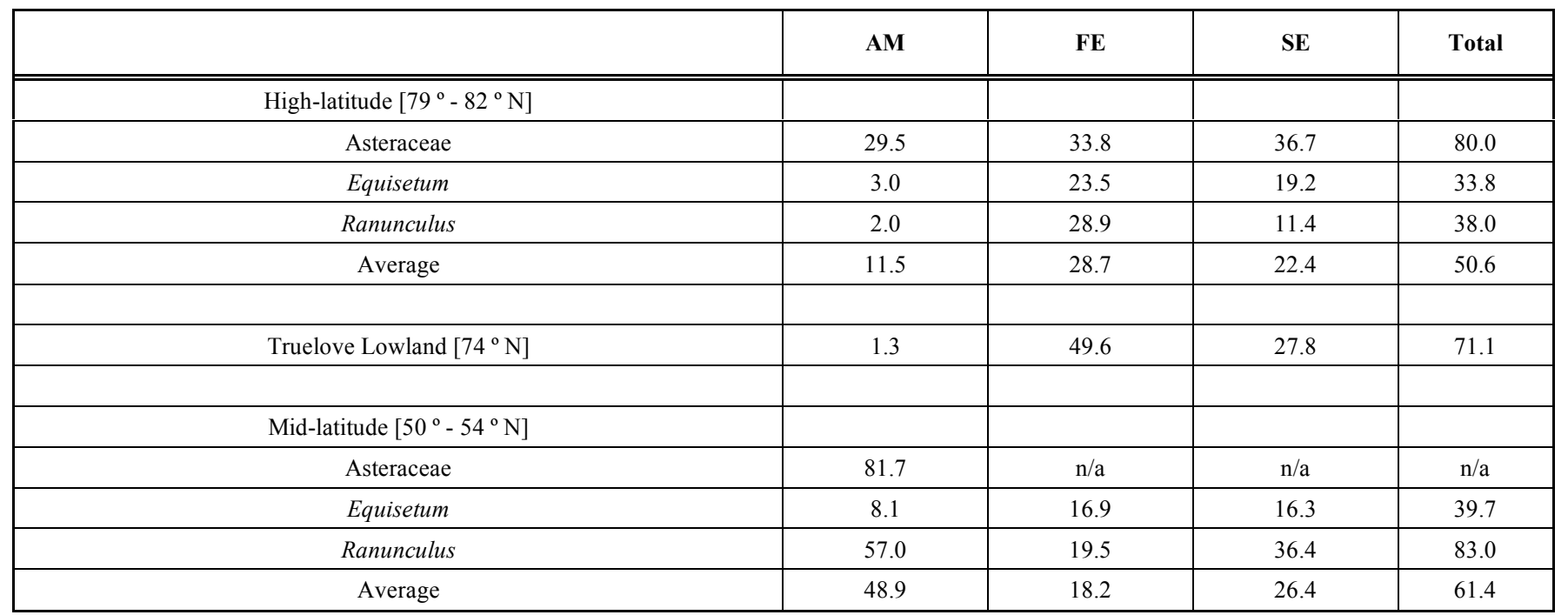

${ }^{a}$ High-latitude Asteraceae data available from Ormsby et al. [8]. Equisetum data available from Hodson et al. [18]. Ranunculus data [this publication]. Midlatitude AM data only, from Allen et al. [7]. Truelove Lowland data [eight genera] from Peters et al. [19].

${ }^{n / a}$ Data not available.

fungal colonization in mid-latitude sites was more than twice as abundant as from High Arctic sites (Tables 2, 3).
AM hyphae are aseptate and $3-6 \mu \mathrm{m}$ wide (Fig. 2A). AM can produce two types of colonization, named for the 

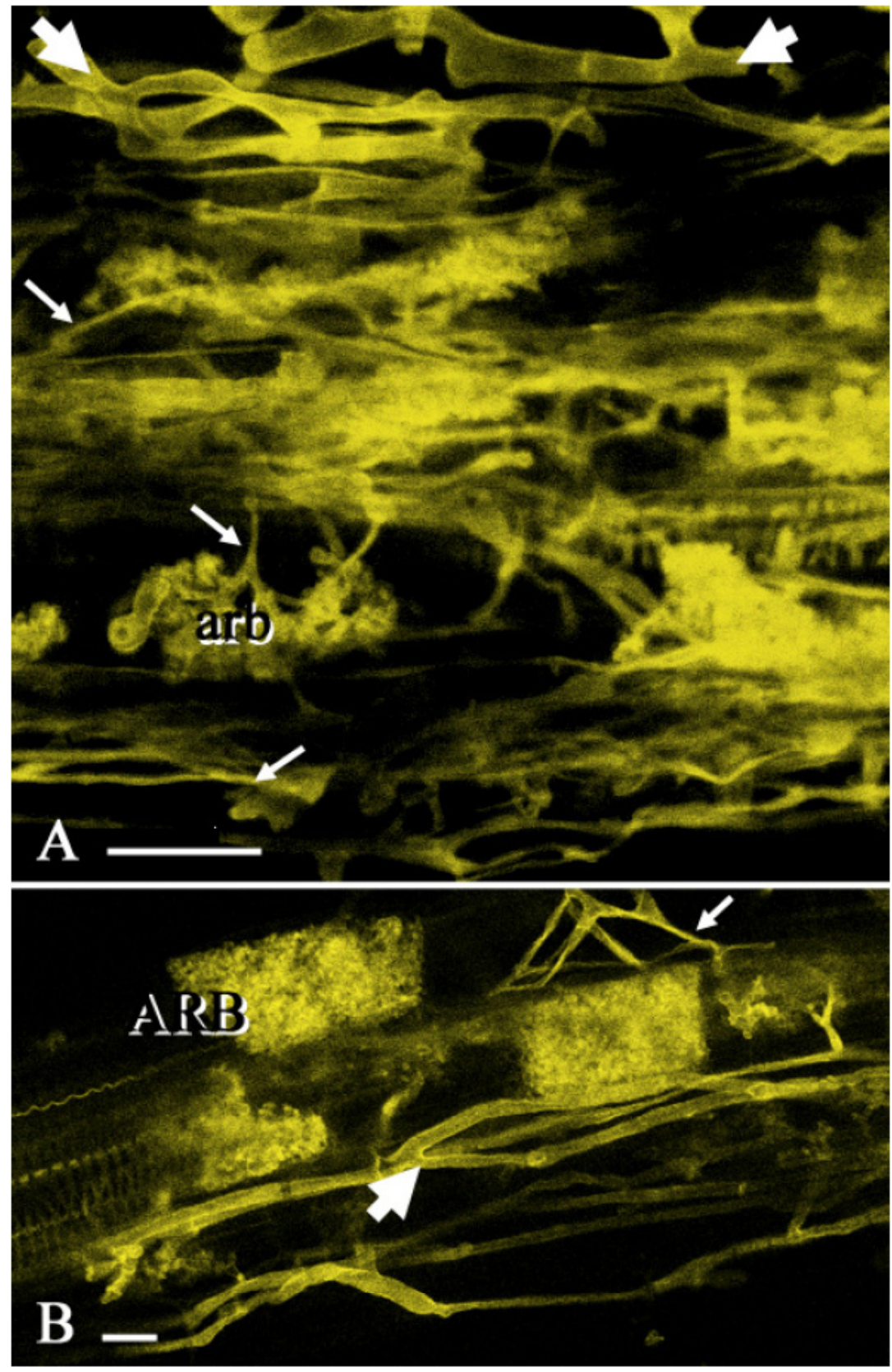

Fig. (2). Arbuscular mycorrhiza $[\mathrm{AM}]$ and fine endophyte [FE] colonization in a Ranunculus cymbalaria root, collected from Shellbrook SK and fixed in formalin, stained with lactofuchsin, and imaged with confocal epifluorescence microscopy. AM hyphae [large arrowheads] and AM arbuscules [ARB]; FE hyphae [small arrows] and FE arbuscules [arb]. Bars $=20 \mu \mathrm{m}$.

plant genera in which they were first characterized. Arumtype AM produce ramified intracellular branches called arbuscules as sites of nutrient exchange with the host plant (Fig. 2B), whereas Paris-type AM produce intracellular hyphal coils. In the present study, hyphal coils were found only in $R$. sceleratus and $R$. macounii roots collected from White Cap, Saskatchewan. The abundance of AM arbuscules (Fig. 2A) and vesicles (not shown) was correlated $(\mathrm{r}=0.58)$, but these structures were common only for mid-latitude sites. In Ranunculus roots sampled for this study, AM hyphae were rare for High Arctic sites compared to samples from the mid-latitudes (Table 2), and in the Arctic AM hyphae were associated with few arbuscules or vesicles.
FE hyphae are aseptate and $1-1.5 \mu \mathrm{m}$ wide (Figs. 2-4 [9]). In Ranunculus FEs form extensive intercellular hyphal arrays (Figs. 3, 4) that produce arbuscules (Figs. 3A, B and 4) and vesicles (Fig. 3C). The morphology of AM and FE arbuscules differs, in that AM arbuscules typically fill entire plant root cells (Fig. 2B) whereas FE arbuscules do not (Figs. (2A) and (3A, B)). FE arbuscules and vesicles were particularly abundant for Ranunculus collected on Axel Heiberg Island and Ellesmere Island in 1985 and on Axel Heiberg Island in 2004 (Table 2). In general, FEs were relatively more abundant in roots sampled from High Arctic than mid-latitude sites (Table $\mathbf{3}$ ). 


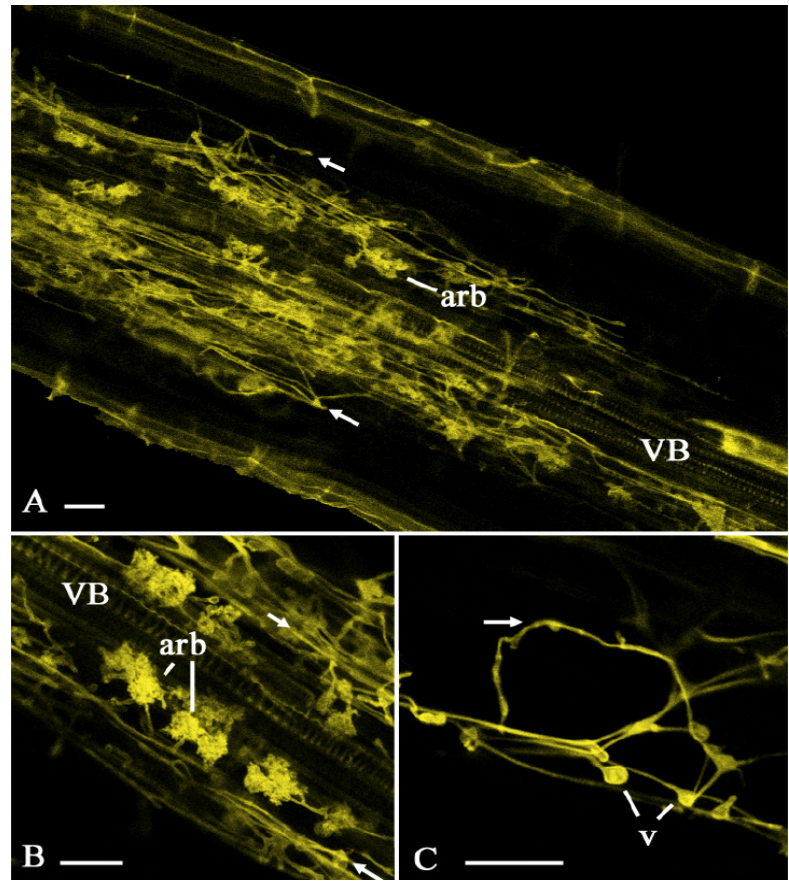

Fig. (3). Fine endophyte colonization in a Ranunculus nivalis roots from Axel Heiberg Island, fixed in formalin, stained with lactofuchsin, and imaged with confocal epifluorescence microscopy. A and B. Hyphae (arrows) and arbuscules (arb) are particularly abundant around the vascular bundle (VB). C. A hypha (arrow) that produced vesicles (V). Bars $=20 \mu \mathrm{m}$.

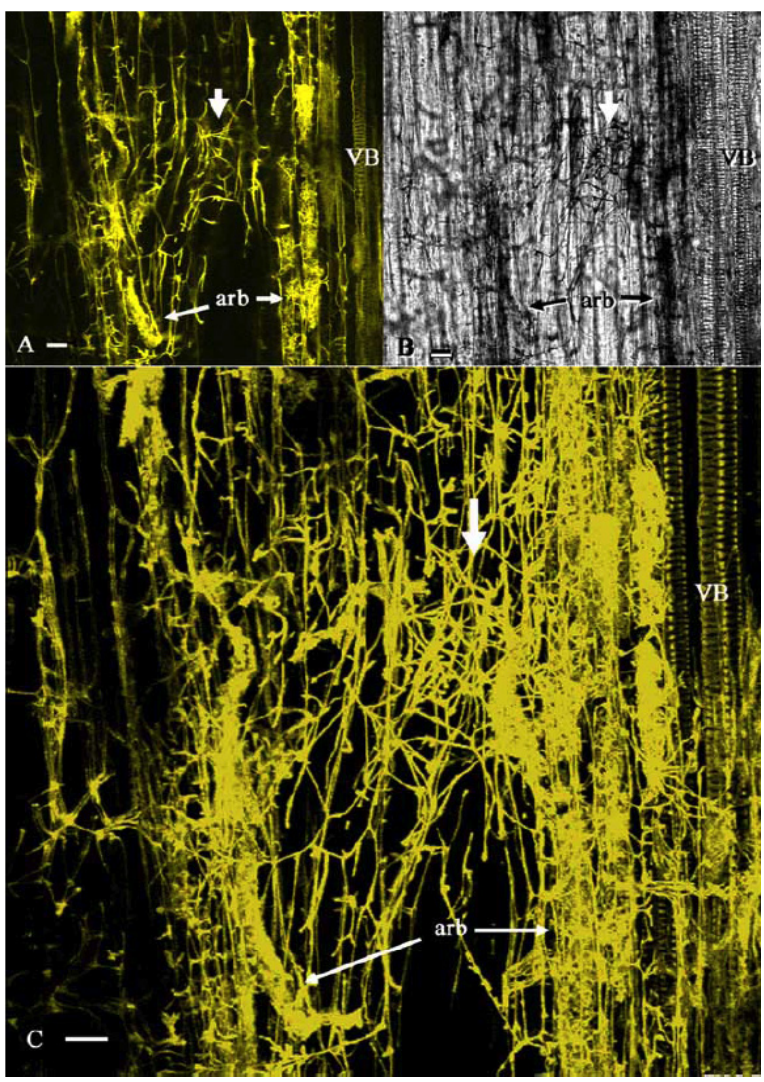

Fig. (4). Fine endophyte [FE] colonization of a Ranunculus nivalis root from Axel Heiberg Island, fixed in formalin, stained with lactofuchsin, and imaged with confocal epifluorescence (A) and simultaneously with transmitted light microscopy (B). FE arbuscules [arb], FE intercellular hyphae [arrowheads], root vascular bundle [VB]. (C) A merged stack of a 47-part confocal z-series spanning about $30 \mu \mathrm{m}$ in depth, of which one slice is shown in $(\mathbf{A}, \mathbf{B})$ reveals the complexity of the FE network. Image by Nathan Allen. Bar $=20 \mu \mathrm{m}$.

Septate endophyte (SE) hyphae have regular cross-walls (Fig. 5A, B), and typically are ascomycetous (reviewed in
[21]). SEs can produce microsclerotia (Fig. 5C) as potential propagules; in our study, microsclerotia were most common 

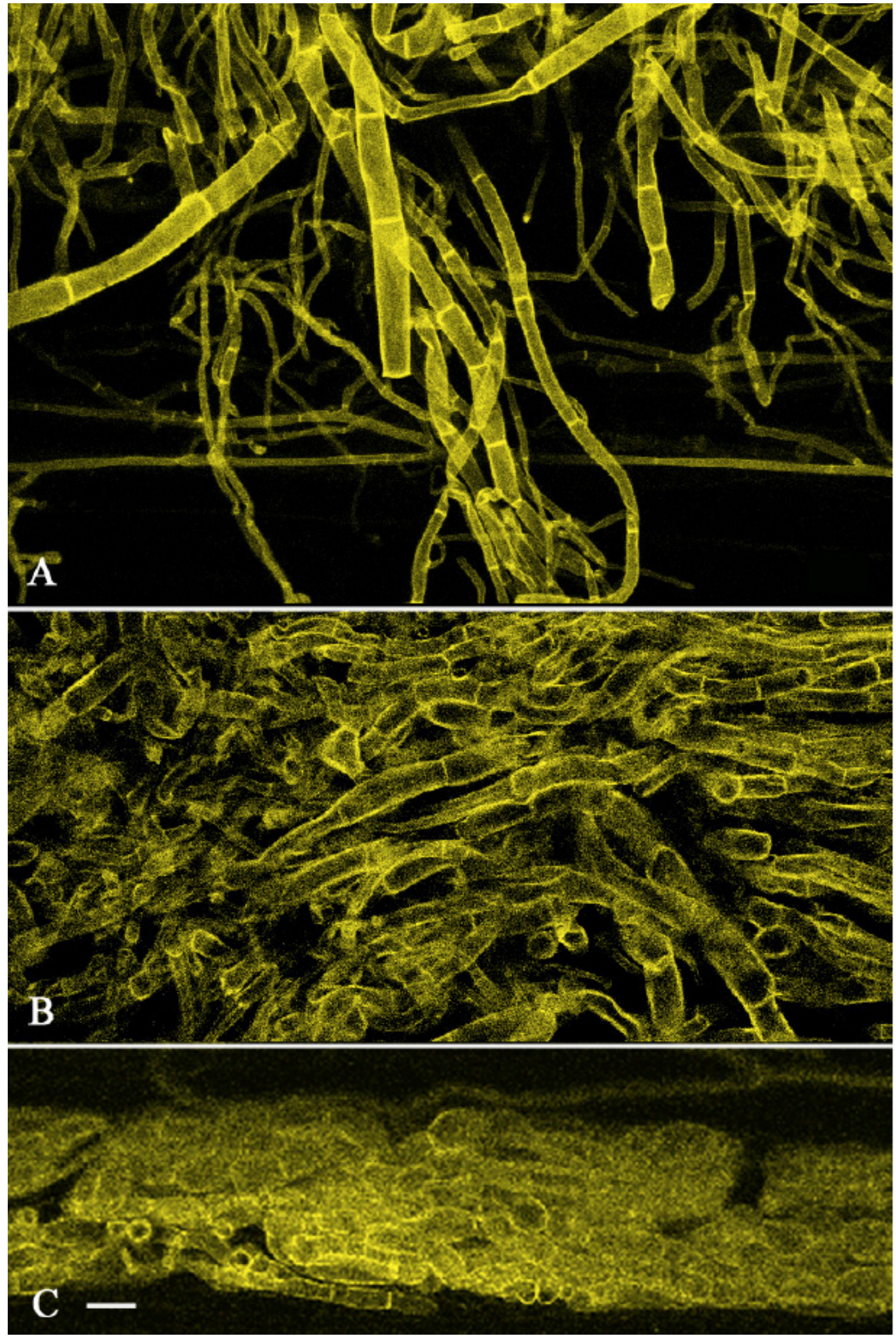

Fig. (5). Septate endophyte [SE] hyphae in Ranunculus sceleratus roots from White Cap, fixed in formalin, stained with lactofuchsin, and imaged with confocal epifluorescence microscopy. Endorhizal hyphae (A) can form aggregates (B) and microsclerotia (C), which are presumptive resting structures. Bar in $\mathrm{C}=20 \mu \mathrm{m}$, for all parts.

in R. sceleratus collected from White Cap. SE hyphae having sufficient melanin in their walls to preclude fluorescence using our imaging method (Fig. 6) were termed dark septate endophytes (DSE). The DSE hyphae were rare in the Ranunculus roots sampled for this study, with the exception of $R$. turneri collected from sites in Yukon Territory in 2006. 


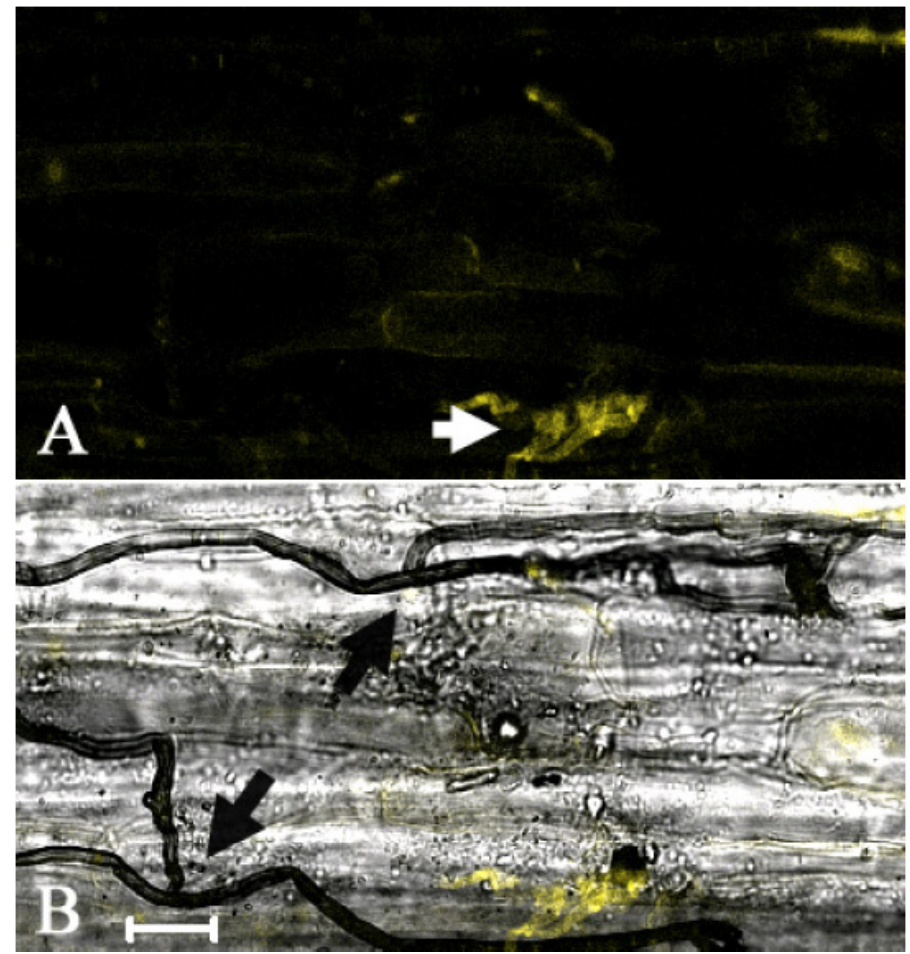

Fig. (6). Dark septate endophyte [DSE] hyphae in a Ranunculus nivalis root from Axel Heiberg Island, fixed in formalin, stained with lactofuchsin, and imaged with confocal epifluorescence microscopy. (A) An optical section through an arbuscular mycorrhiza hypha fluoresces under these conditions [white arrowheads], whereas the melanized walls of DSE hyphae (black arrows in B) do not. Note the characteristic right-angle branching pattern of the DSE hyphae. Bar in B $=20 \mu \mathrm{m}$, for both.

Colonization by SE and DSE hyphae is pooled in Table 2. Overall, SE colonization was about three-fold higher in mid-latitude than High Arctic sites (Table 3).

\section{DISCUSSION}

The most notable finding in the present study is that FEs were the predominant endorhizal morphotype in Ranunculus growing on high-latitude tundra sites, where they accounted for more than two thirds of the total root colonization. FEs were found at less than a quarter of root intersects for mid-latitude samples. In contrast, AM were rare in Ranunculus roots from high-latitude sites, but abundant in mid-latitude plants.

Roots of Ranunculus nivalis collected in 2004 on Axel Heiberg Island (ca $80{ }^{\circ} \mathrm{N}$ ) contained FE hyphae, and these clearly formed arbuscules [7]; however, FE abundance in these specimens was not evaluated in that study. FEs have also been found in plants that were expected to host $\mathrm{AM}$ across for a latitudinal transect encompassing $73^{\circ} \mathrm{N}-78^{\circ} \mathrm{N}$ in the western and central Canadian High Arctic [6]. FEs have been shown to have effects comparable to AM regarding phosphorus uptake [21] and translocation [13], and so AM and FEs might be expected to have similar ecological roles. These possibilities merit further investigation.

Our FE abundance data may nevertheless be an underrepresentation of the predominance of Ranunculus FEs in tundra biomes, since as illustrated in this paper $R$. nivalis root segments typically contained multiple FE hyphae and arbuscules. Similarly, we found that high levels of FE colonization are characteristic of a diversity of plant species growing above $74^{\circ} \mathrm{N}[8,18,19]$. Consistent with our results, Olsson et al. [6] found that $42 \%$ of the root length (assessed by a quantitative microintersect method) of $R$. sabinei collected from Ellef Ringnes Island $\left(78^{\circ} \mathrm{N}\right)$ was colonized by FE. They also found [6] that FE colonization of Asteraceae roots on Banks Island $\left(73^{\circ} \mathrm{N}\right.$ ) ranged between $0.8 \%$ (Potentilla pulchella) and $17 \%$ (Erigeron eriocephalus). Crush [10] reported averages of $10 \% \mathrm{FE}$ colonization for ten grass species and $19 \%$ FE colonization for five Trifolium species, both growing on unfertilized soils in New Zealand's Mackenzie Basin, which is about $44^{\circ} \mathrm{S}$. It is likely that FEs are more abundant than previously appreciated in plants of the high latitudes, and are likely to therefore have a significant role in tundra biomes. The observation of low occurrence of FEs in mid-latitude samples, however, must be further explored, as even when stained with lactofuchsin and visualized by epifluorescence microscopy, FEs can potentially be overlooked when there are abundant AM fungi.

DSEs, in contrast to most endorhizal fungi and in particular to FEs, are straightforward to identify using transmitted light microscopy, and have frequently been identified in the roots of tundra plants. The intensity of melanization can vary with species and life cycle stage, so the distinction between $\mathrm{SE}$ and DSE is seldom precise, nor consistent between research groups. Previously [18] and in this paper, SE and DSE hyphae are distinguished on the basis of whether or not they fluoresced following lactofuchsin staining: lightly pigmented SE hyphae are detected by fluorescence microscopy following lactofuchsin staining, whereas darkly pigmented DSE hyphae are not. SE fungi have a diversity of nonnutritive roles, reviewed in [21]. In contrast, the role for DSE in nutrient translocation requires further clarification [23, 
24]. In this study, Ranunculus roots collected across a wide latitudinal transect were colonized by SE fungi, and to a much lesser extent by DSE fungi. In collaboration with R. Rodriguez and R. Redman, we have begun studying SEs associated with high-latitude plants, with the hope of identifying species that contribute to tolerance of cold, nutrient-limited conditions with widely varying day length.

\section{ACKNOWLEDGEMENTS}

We are pleased to acknowledge funding from NSERC DG for JFB and SGWK, and an NSERC USRA award for XJW. We also acknowledge The Polar Continental Shelf Project, Natural Resources Canada for logistic support during the 2004 collecting season, and the cooperation of the Kwanlin Dun First Nation and the Government of the Yukon Territory during the 2006 collecting season. The confocal Zseries animation was taken by Nathan Allen. This is PCSP publication number 04609 .

\section{ABBREVIATIONS}

$\mathrm{AM}=$ Arbuscular mycorrhiza
$\mathrm{DSE}=$ Dark septate endophyte
$\mathrm{FE}=$ Fine endophyte
$\mathrm{MQM}=$ Multiple quantitation microintersect
$\mathrm{PCSP}=$ Publication number 04609
$\mathrm{SE}=$ Septate endophyte

\section{REFERENCES}

[1] Whittemore AT. Ranunculus. Flora of North America Editorial Committee, Flora of North America North of Mexico. New York and Oxford 1997; pp. 88-135.

[2] Read DJ, Haselwandter K. Observations on the mycorrhizal status of some alpine plant communities. New Phytol 1981; 88: 341-52.

[3] Vare H, Vestberg M, Eurola S. Mycorrhiza and root-associated fungi in Spitsbergen. Mycorrhiza 1992; 1: 93-104.

[4] Bledsoe C, Klein P, Bliss LC. A survey of mycorrhizal plants of Truelove Lowland, Devon Island, N.W.T. Canada. Can J Bot 1990; 68: 1848-56.

[5] Dalpé Y, Aiken SG. Arbuscular mycorrhizal fungi associated with Festuca species in the Canadian High Arctic. Can J Bot 1998; 76: 1930-8.
[6] Olsson PA, Eriksen B, Dahlberg A. Colonization by arbuscular mycorrhizal and fine endophyte fungi in the herbaceous vegetation in the Canadian High Arctic. Can J Bot 2004; 82: 1547-56.

[7] Allen N, Nordlander M, McGonigle T, Basinger J, Kaminskyj S. Arbuscular mycorrhizae on Axel Heiberg Island $\left[80^{\circ} \mathrm{N}\right]$ and at Saskatoon [52 $\left.{ }^{\circ} \mathrm{N}\right]$ Canada. Can J Bot 2006; 84: 1094-100.

[8] Ormsby A, Hodson E, Li Y, Basinger J, Kaminskyj S. Arbuscular mycorrhizae associated with Asteraceae in the Canadian High Arctic: the value of herbarium archives. Can J Bot 2007; 85: 599606.

[9] Thippayarugs S, Bansal M, Abbott KL. Morphology and infectivity of a fine endophyte in a Mediterranean environment. Mycol Res 1999; 103: 1369-79.

[10] Crush JR. Occurrence of mycorrhizae in soils of Mackenzie Basin, Canterbury, New Zealand. NZ J Agric Res 1975; 18: 361-4.

[11] Smith SE, Read DJ. Mycorrhizal symbioses. $2^{\text {nd }}$ ed: London, UK: Academic Press 1997.

[12] Peterson RL, Massicote H, Melville LH. Mycorrhizas: anatomy and cell biology. Wallingford UK: CABI 2004.

[13] Gianinazzi-Pearson V, Morandi D, Dexheimer J, Gianinazzi S. Ultrastructural and ultracytochemical features of a Glomus tenuis mycorrhiza. New Phytol 1981; 88: 633-9.

[14] Porsild A. Illustrated Flora of the Canadian arctic archipelago. Ottawa: National Museum of Canada 1985.

[15] Budd A. Budd's Flora of the Canadian prairie provinces. Hull, Quebec: Agriculture Canada Research Branch 1987.

[16] Moss EH, Packer JG. Flora of Alberta. Toronto, ON: University of Toronto Press 1983.

[17] Kaminskyj SGW. Effective and flexible methods for visualizing and quantifying endorhizal fungi. In: Siddiqui ZA, Akhtar MS, Futai K, Eds. Mycorrhizae: sustainable agriculture and Forestry. Dordrecht, The Netherlands: Springer-Verlag; 2008; pp. 337-49.

[18] Hodson E, Shahid F, Basinger J, Kaminskyj S. Fungal endorhizal associates of Equisetum species from Western and Arctic Canada. Mycol Prog 2009; 8: 19-27.

[19] Peters C, Basinger JF, Kaminskyj SGW. Endorhizal fungi associated with vascular plants on Truelove Lowland, Devon Island, Nunavut, Canadian High Arctic. In: Columbus F, Ed. Tundras: Vegetation, Wildlife and Climate Trends. Hauppauge, NY: Nova Publishers 2009 (in press).

[20] McGonigle TP, Miller MH, Evans DG, Fairchild GL, Swan JA. A new method which gives an objective measure of colonization of roots by vesicular-arbuscular mycorrhizal fungi. New Phytol 1990; 115: 495-501.

[21] Rodriguez RJ, White JF, Arnold AE, Redman RS. Fungal endophytes: diversity and functional roles. New Phytol 2009; 182: 314-30.

[22] Powell CL, Daniel J. Mycorrhizal fungi stimulate uptake of soluble and insoluble phosphate fertilizer from a phosphate-deficient soil. New Phytol 1978; 80: 351-8.

[23] Haselwandter K, Read DJ. Fungal association of roots of dominant and sub-dominant plants in high-alpine vegetation systems with special reference to mycorrhiza. Oecologia 1980; 45: 57-62.

[24] Jumpponen A. Dark septate endophytes: are they mycorrhizal? Mycorrhiza 2001; 11:207-11. 